\title{
Solvatochromic and Ligand Effects in Ultrafast Intramolecular Electron Transfer in Fe-based Molecular Photosensitizers
}

\author{
Kristjan Kunnus ${ }^{1, *}$, Lin $\mathrm{Li}^{1}$, Marco Reinhard ${ }^{1}$, Sergey Koroidov ${ }^{1}$, Kasper S. Kjaer ${ }^{1}$, Kathryn \\ Ledbetter ${ }^{1}$, Kiryong Hong ${ }^{1}$, Elisa Biasin ${ }^{1}$, Amy Cordones-Hahn ${ }^{1}$, Kelly J. Gaffney ${ }^{1}$ \\ ${ }^{1}$ Stanford PULSE Institute, SLAC National Accelerator Laboratory, Menlo Park, CA 94025, USA
}

\begin{abstract}
Metal-to-ligand charge-transfer (MLCT) excited state lifetimes of $\left[\mathrm{Fe}(\mathrm{CN})_{4}\left(2,2^{\prime} \text {-bipyridine }\right)\right]^{2-}$ and $\left[\mathrm{Fe}(\mathrm{CN})_{4}(2,3\right.$-bis(2-pyridyl $)$ pyrazine $\left.)\right]^{2-}$ exhibit strong solvent and ligand dependence. We conclude that these effects can be described with Marcus-like model where changes in the MLCT energy correspond directly to the changes in the electron transfer driving force and all the other factors (e.g. reorganization energy) can be considered constant.
\end{abstract}

\section{Introduction}

Photosensitizer materials control the initial steps of solar energy conversion into chemical and electrical energy, for example during operation of photo-electrochemical solar cells [1]. A considerable effort has been dedicated into finding cheaper and more efficient photosensitizers that could replace the currently common materials based on expensive noble metals (e.g. Ru) by their cheap and abundant 3d analogues. Recently $92 \%$ electron injection efficiency was reported for a Fe-centered molecular photosensitizer - a considerable advancement compared to usually very low efficiencies of Fe coordination complexes [2].

In this contribution we present investigations of solvent-dependent metal-to-ligand charge-transfer (MLCT) relaxation dynamics in two mixed-ligand $\left[\mathrm{Fe}(\mathrm{CN})_{4}(\mathrm{bpy}, \mathrm{bpp})\right]^{2-}$ (bpy=2,2'-bipyridine, $b p p=2,3$-bis(2-pyridyl)pyrazine) photosensitizer model systems (Fig. 1). These complexes show significant solvatochromic effect as a function of solvent Lewis acidity (acceptor number) [3], which allows us to study MLCT energy dependence of the electron back-transfer time scale.

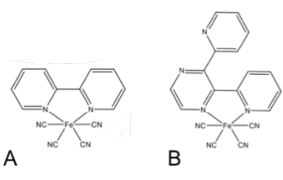

Fig. 1. Chemical structures of $(\mathrm{A})\left[\mathrm{Fe}(\mathrm{CN})_{4}(\mathrm{bpy})\right]^{2-}$ and $(\mathrm{B})\left[\mathrm{Fe}(\mathrm{CN})_{4}(\mathrm{bpp})\right]^{2-}$.

\footnotetext{
* Corresponding author: kkunnus@stanford.edu
} 

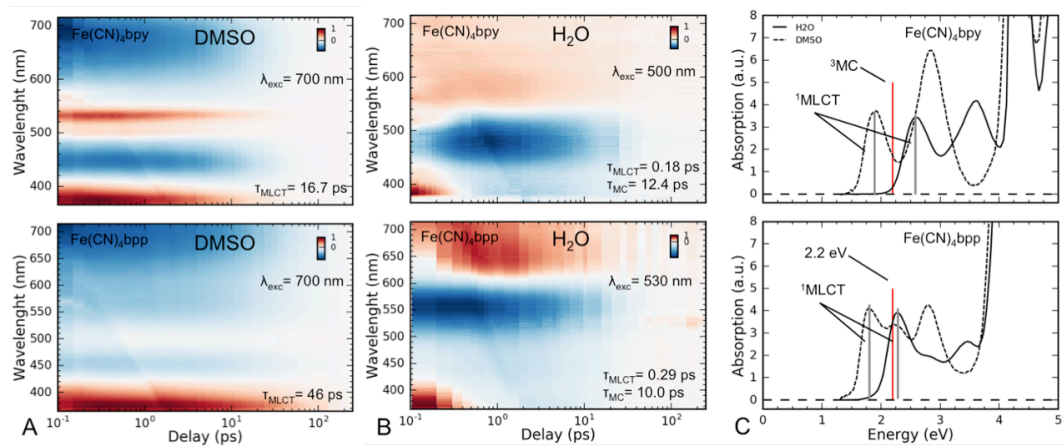

Fig. 2. Femtosecond transient absorption data of $\left[\mathrm{Fe}(\mathrm{CN})_{4}(\mathrm{bpy}, \mathrm{bpp})\right]^{2-}$ in $(\mathrm{A}) \mathrm{DMSO}$ and $(\mathrm{B}) \mathrm{H}_{2} \mathrm{O}$. First row depicts data of $\left[\mathrm{Fe}(\mathrm{CN})_{4}(\mathrm{bpy})\right]^{2-}$ and second row data of $\left[\mathrm{Fe}(\mathrm{CN})_{4}(\mathrm{bpp})\right]^{2-}$. Negative ground state (GS) spectra are scaled for better comparison. (C) Solvatochromism of the UV/vis aborption spectra and the energies of low energy metal-centred states.

\section{Results}

MLCT relaxation dynamics was probed using UV/vis transient absorption in DMSO and $\mathrm{H}_{2} \mathrm{O}$ solutions (Fig. 1A and $1 \mathrm{~B}$; not displayed are $\left[\mathrm{Fe}(\mathrm{CN})_{4}(\mathrm{bpy})\right]^{2-}$ results in methanol). MLCT states show clear solvent-independent excited state absorption (ESA) signature associated to bpy/bpp-ligand radicals $<400 \mathrm{~nm}$ and bpy-ligand radicals around $530 \mathrm{~nm}$. MLCT ESA features decay concomitantly with the ground state bleach (GSB) recovery in DMSO solutions of all three complexes (lifetime $16.7 \mathrm{ps}$ and $46 \mathrm{ps}$ in $\left[\mathrm{Fe}(\mathrm{CN})_{4}(\mathrm{bpy}, \mathrm{bpp})\right]^{2-}$, respectively). Global decay analysis reveals also a second few picosecond component which most likely can be associated with vibrational cooling of the MLCT excited state [4].

Qualitatively different dynamics is observed in $\mathrm{H}_{2} \mathrm{O}$ solutions of $\left[\mathrm{Fe}(\mathrm{CN})_{4}(\mathrm{bpy}, \mathrm{bpp})\right]^{2-}$, where MLCT ESA features decay without GSB recovery with 180 fs and 280 fs time constants. Our recent time-resolved Fe K $\beta$ X-ray emission spectroscopy (XES) experiment at the LCLS on $\left[\mathrm{Fe}(\mathrm{CN})_{4}(\text { bpy) }]^{2-}\right.$ in $\mathrm{H}_{2} \mathrm{O}$ revealed that the MLCT state decays into a triplet metal-centred $\left({ }^{3} \mathrm{MC}\right)$ excited state [5]. This enables us to assign unambiguously also the 10 ps intermediate of $\left[\mathrm{Fe}(\mathrm{CN})_{4}(\mathrm{bpp})\right]^{2-}$ to a ${ }^{3} \mathrm{MC}$ excited state.

Energetics of $\mathrm{MC}$ excited states was investigated with Fe $2 \mathrm{p} 3 \mathrm{~d}$ resonant inelastic X-ray scattering (RIXS) [6]. These reveal that lowest MC state energies are identical in both complexes and that the energy of lowest ${ }^{3} \mathrm{MC}$ state at the ground state geometry is $\mathrm{E}\left({ }^{3} \mathrm{~T}_{1 \mathrm{~g}}\right)=$ $2.2 \mathrm{eV}$ (Fig. 1C).

\section{Discussion and Conclusions}

Given the energies of the excited states in studied complexes there are two possible MLCT deactivation mechanism: 1) ${ }^{1,3}$ MLCT $->{ }^{1} \mathrm{~A}_{1 \mathrm{~g}}$ or 2$){ }^{1,3} \mathrm{MLCT}->^{3} \mathrm{~T}_{1 \mathrm{~g}}$. We can immediately exclude the former because in analogous $\mathrm{Ru}$ mixed-ligand complexes with similar or lower MLCT energies this pathway leads to lifetimes $>10$ ns, i.e. three orders of magnitude slower than observed here [7]. Additionally, because ${ }^{3} \mathrm{MC}$ was found to deactivate the MLCT state in $\left[\mathrm{Fe}(\mathrm{CN})_{4}(\mathrm{bpy}, \mathrm{bpp})\right]^{2-} \mathrm{H}_{2} \mathrm{O}$ solution, it is a reasonable that ${ }^{1,3} \mathrm{MLCT}->^{3} \mathrm{~T}_{1 \mathrm{~g}}$ pathway is active also in all the other studied solutions here, even if no intermediate was detected.

In order to explain the observed MLCT lifetimes we invoke a Marcus-like model and assume that solvatochromic effect influences only the MLCT energy, corresponding to 


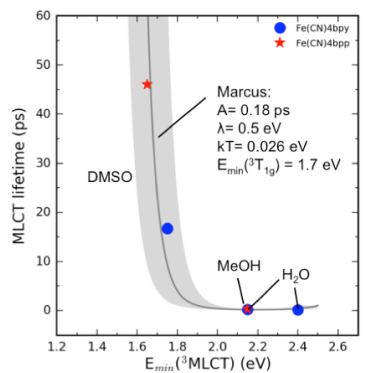

Fig. 3. MLCT lifetime dependence on ${ }^{3}$ MLCT energy. Shaded area corresponds to $+/-0.1 \mathrm{eV}$ shift of the Marcus curve.

observed UV/vis peak shifts (Fig. 2C). Therefore $k_{E T}=A^{-1} \exp \left(-\Delta G^{\#} / k T\right), \Delta G^{\#}=(\Delta G+\lambda)^{2} / 4 \lambda$, where $\Delta \mathrm{G}$ is driving force and $\lambda$ is reorganization energy. Driving force is equal to $\Delta \mathrm{G}=$ $\mathrm{E}_{\min }\left({ }^{3} \mathrm{~T}_{1 \mathrm{~g}}\right)-\mathrm{E}_{\min }\left({ }^{3} \mathrm{MLCT}\right)$, where $\mathrm{E}_{\min }$ denotes energy at the potential surface minimum. By taking the pre-exponential factor A equal to MLCT lifetime in $\left[\mathrm{Fe}(\mathrm{CN})_{4}(\mathrm{bpy})\right]^{2-} \mathrm{H}_{2} \mathrm{O}$ solution, we find that $\lambda=0.5 \mathrm{eV}$ gives electron transfer time constants that qualitatively agree with the observed MLCT lifetimes of $\left[\mathrm{Fe}(\mathrm{CN})_{4}(\mathrm{bpy}, \mathrm{bpp})\right]^{2-}$ in all the solvents (Fig. 3). Although quantitative modelling of the MLCT lifetimes is not possible, these results show that the electron back-transfer dynamics in $\left[\mathrm{Fe}(\mathrm{CN})_{4}(\mathrm{bpy}, \mathrm{bpp})\right]^{2-}$ is consistent with the ${ }^{1,3}$ MLCT $->^{3} \mathrm{~T}_{1 \mathrm{~g}}$ pathway and the dominant effect of the solvatochromism is change in the driving force. Latter explains why the effect of solvatochromism is so dramatic, because $\mathrm{k}_{\mathrm{ET}} \sim \exp \left[\mathrm{E}_{\mathrm{GS}}\left({ }^{1} \mathrm{MLCT}\right)^{2}\right]$.

This work by was supported by the U.S. Department of Energy, Office of Science, Basic Energy Sciences, Chemical Sciences, Geosciences, and Biosciences Division.

\section{References}

1. A. Hagfeldt, G. Boschloo, L. Sun, L. Kloo, and H. Pettersson, Chem. Rev. 110, 6595 (2010).

2. T. C. B. Harlang et al., Nat. Chem. 7, 883 (2015).

3. H. E. Toma, M. S. Takasugi, J. Sol. Chem. 12, 547 (1983).

4. W. Zhang et al., Chem. Sci. 101, 1298 (2016).

5. K. S. Kjaer et al., Phys. Chem. Chem. Phys. 20, 4238 (2018).

6. K. Kunnus et al., unpublished.

7. M. T. Indelli, C. A. Bignozzi, F. Scandola, J.-P. Collin, Inorg. Chem. 37, 6084 (1998). 